\title{
Study on the Correlation of Civil Servant Organization Justice and Turnover Tendency: Based on the External Job Opportunities as Mediating Variable
}

\author{
Li Tao ${ }^{1}$ Yang Weimei ${ }^{1} \quad$ Han $\mathbf{y i}^{1}$ \\ ${ }^{\mathbf{1}}$ School of Public Management, Guangxi University for Nationalities, Nanning, P.R.China, 530006 \\ (Email: 1t75@163.com, yangweimei1104@qq.com, hanyi541200@126.com)
}

\begin{abstract}
The purpose of this paper is mainly analysis the correlation of official organization justice and turnover tendency. , make some questionnaires survey on the civil servants, and recycle the data of the questionnaires. Then the questionnaires are made quantitative analysis by the statistical software of SPSS 17.0 for windows. As a result of Pearson correlation coefficient testing and regression analysis testing, we get the relevance conclusions about the civil servant organization justice and external job opportunity.
\end{abstract}

Keywords: civil servant; organization justice; external job opportunity; turnover tendency

\section{Introduction}

The law of the personnel flow is that the flow and scale of personnel is decided by the economic development differentiation among the different regions. Moreover, the political and economic system which is belonging to the human resource management will support or change this flow and expand or narrow the scale. Personnel flow is no longer a relatively static short-term change which is related to the unemployment, but it becomes a dynamic long-term change which is involve the economic growth. Thus, the best way to manage the rational civil servant refers to use of human resources. It is not only the important condition to give a full play of personnel effect and objective request of the market economy, but also is a main part for the reform of civil servant system.

The early study of organizational justice was made by famous scholars, such as Humans,
Blau , Adams, Walster, Berscheid \& Waister and so on. They focus their point on the discussion of distributive justice. Adams proposed a sense of fairness which was called fair distribution mainly refers to the justice of distribute remuneration quantity and it emphasis more in distribute result. Therefore, it can be defined as "the staff who would feel the justice of distributes remuneration quantity. In consideration of justice of distribute neglect the distribute process before the distribute result, Thibaut\&Walker put forward the procedural justice theory that was published in the monograph which is talk about the justice problem of legal proceeding. According to the research of the difference judicial proceeding effect on satisfying of trial result and the sense of fairness in the trial process, they proposed two important concepts, which are process control and decision control. The study of procedural justice was extended to the organizational environment and so on by Leventhal, which obtained many achievements.

The follow-up scholars are transferring their target gradually to research of procedural justice which has become the main point of the organization justice theory. Thibaut \& Walker contend the definition of the procedural justice is the justice sense to the decision process while Forger \& kinovsky thought that it was a way of justice sense to decide the staff's payment quantity. In brief, all the concerns are about justice of decision process pr tool.

In 1986, Bies \& Moag put forward the conception of interaction justice by research the relationship between interpersonal interaction and a sense of fairness when procedure execution. It refers to whether individual could feel justice treatment before the decision was made by organization. 
Greenberg divided the interactive justice into interpersonal justice and informational justice.

In the job market, employees will have the intension to find job when the outside could offer many job opportunities. Arnold \& Feldman's individual model illustrates such kind of relationship. Wang Bingbing argues that the portion of the supply and demand in the labor market is an important environmental factor affecting employee turnover, while Zhang Shuhan thought that the individual cognitive potential work opportunity would also affect the turnover inclination.

From the traditional definition of turnover, scholars have divided it into two categories. One is voluntary turnover: it including organizational factors and personal factors which could cause the turnover, the other is the involuntary turnover: it including the dismissal 、 retirement and so on. $\mathrm{Su}$ Fangguo pointed out that, in general, the passive turnover can promote the development of corporation while the staff chooses to turnover at his own will cause demoralized result and losing investment of human resources capital. Therefore, the management practitioner or the theory researcher will pay more attention on the initiative demission.

\section{Research method}

(1) Research Framework

This essay is mainly focus on the relevance of organizational justice 、 external job opportunity and turnover tendency. The theory framework is showed as Fig. 1:

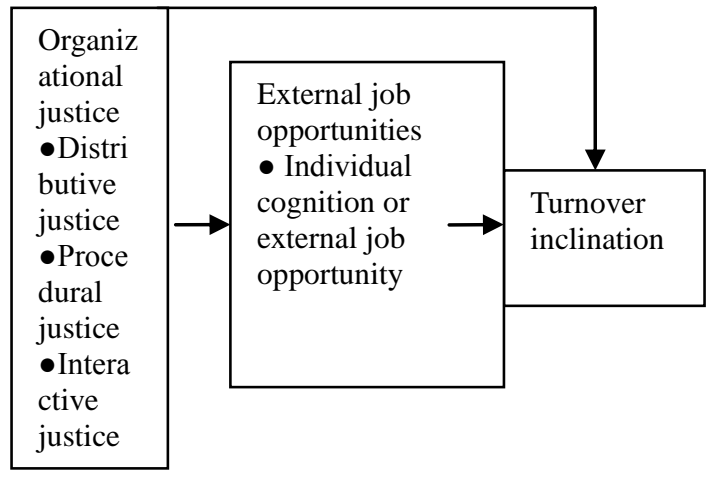

Fig. 1: Research Framework

(2) Research Hypothesis

According to the literature review and research framework which is shown above the essay, the research proposed the following hypothesis:

Hypothesis 1: From each construction surface, the "organizational justice" is negatively related to "turnover tendency". Hypothesis 2: According to the intermediary function, the organizational justice will affect the turnover tendency.

(3) Operant Definition

(1)The definition of independent variable

Distribute Justice

According to the definition proposed by Liu Tingyang, staff's fair distributive justice means procedure justice.

Thibaut.J.\&Walker. L divided the discussion making into two parts, namely, process and decision. The former refers to participants presented the control action which is presented information evidence and advice before making the decision. The latter refers to control right for management institution to make a decision to realistic.

Interactive Justice. Bie. R.T \& Moag.J.S thought that aside from the distributive justice and procedural justice, individual perception of fairness justice would also decide by the interpersonal relation cognition based on

(2)Intervening Variable

The external job opportunity is refers to individual cognition on the possibility of external job opportunities.

(3)The definition of dependent variable turnover tendency

It means the possibility for civil servant to accept the new job.

\section{3 .Positive analysis}


The research has put out 300 pieces questionnaire to public department and the recovery rate is $60.3 \%$. The 181 pieces of effective questionnaire will be entered and keep into the SPSS 17.00 program file.

(1) Sample reliability

The questionnaire of research include 3 parts, namely, organizational justice 、 external job opportunity and turnover tendency. Overall, the whole Cronbach's a coefficient of each research is more than 0.8 , which is higher than 0.6. Thus, the reliability of the whole questionnaire is worth to be trusted.

(2) Correlation Analysis

From the table 3-1, it can be found that the coefficient of interactional justice and turnover tendency are all reach the negative correlation. It shows the close relationship between each independent variable and turnover tendency.

\begin{tabular}{|l|l|l|}
\hline \multicolumn{1}{|c|}{ Dependent variable } & \multicolumn{2}{|c|}{ Turnover tendency } \\
\cline { 2 - 3 } $\begin{array}{l}\text { Independent } \\
\text { Variable }\end{array}$ & $\begin{array}{c}\text { Relative } \\
\text { coefficient }\end{array}$ & Significance Sig. (2-tailed) \\
\hline Procedural justice & $-0.690^{* *}$ & 0.000 \\
\hline Distributive justice & $-0.655^{* *}$ & 0.000 \\
\hline Interactional justice & $-0.522^{* *}$ & 0.000 \\
\hline
\end{tabular}

PS: $* *$ Correlation is significant at the 0.01 level (2-tailed).

Table 3-1 The correlation analysis between organizational justice and turnover tendency $(\mathrm{N}=502)$

Therefore, according to understand the relation among this variables, it can provide the research foundation to regression analysis.

(3) Regression Analysis

(1) The relationship between organizational justice and turnover tendency

As stepwise multiple regression analysis in table 3-2 shown, when $\mathrm{p}<.001$ enters to the level, the three independent variables of occupational values can predict efficiently that the independent variable of turnover tendency. The sequence of them entering regression model is procedural justice 、 interactional justice and distribute justice. The multiple correlation coefficients of dependent variables for procedural justice is 0.177 , the standard error is 0.022 , and $\mathrm{t}=0.177 / 0.022=8.05$, thus the practical significant level of $t$ value is $p$ value, here Sig. $<0.001$, so the regression coefficient of dependent variable for procedural justice shows highly significant. When $\mathrm{p}<.001$ enters to the level, The multiple correlation coefficients of dependent variables for interactional justice is 0.253 , the standard error is 0.025 , and $\mathrm{t}=0.253 / 0.025=10.12$, thus the practical significant level of $t$ value is $p$ value, here Sig. $<0.001$, so the regression coefficient of dependent variable for interactional justice shows highly significant. When $\mathrm{p}<.001$ enters to the level, the multiple correlation coefficients of dependent variables for distribute justice is 0.116 , the standard error is 0.023 , and $\mathrm{t}=0.116 / 0.023=5.04$, thus the practical significant level of $\mathrm{t}$ value is $\mathrm{p}$ value, here Sig. $<0.001$, so the regression coefficient of dependent variable for distribute justice shows highly significant.

From the view of the predictive ability of individual variables, the procedural justice, $\Delta$ $\mathrm{R}^{2}=0.475, \mathrm{~F}=454.179$, the corresponding Sig is practical significance probability for $\mathrm{F}$ value, namely $\mathrm{P}$ value, Sig. $<0.001, \mathrm{p}<.001$, so the regression model shows significant; $\beta$ $=.-0.395$, which is negative number, expresses the effect to overall satisfaction is negative, so this conclusion supports hypothesis 1: the better for procedural justice, the lower for turnover inclination.

The interactional justice, $\Delta \mathrm{R}^{2}=0.567$, $\mathrm{F}=329.338$, the corresponding Sig is practical significance probability for $\mathrm{F}$ value, namely $\mathrm{P}$ value. Here Sig. <0.001, $\mathrm{p}<.001$, so the regression model shows significant; $\beta=.-0.395$, which is negative number, expresses the effect to overall satisfaction is negative, so this conclusion supports hypothesis 1: the better for interactional justice, the lower for turnover inclination.

The distribute justice, $\Delta \quad \mathrm{R}^{2}=0.587$, $\mathrm{F}=236.183$, the corresponding Sig is practical significance probability for $\mathrm{F}$ value, namely $\mathrm{P}$ 
value. Here Sig. <0.001, $\mathrm{p}<.001$, so the regression model shows significant; $\beta=.-0.232$, which is negative number, expresses the effect to overall satisfaction is negative, so this conclusion supports hypothesis 1: the better for The $X_{1}, X_{2}, X_{3}$ on behalf of procedural justice, $d$ distribute justice, the lower for turnover inclination.

Therefore, we could obtain the following regression equation:

$$
\mathrm{Y}_{1}=20.714-0.177 \mathrm{X}_{1}-0.116 \mathrm{X}_{2}-0.253 \mathrm{X}_{3}
$$

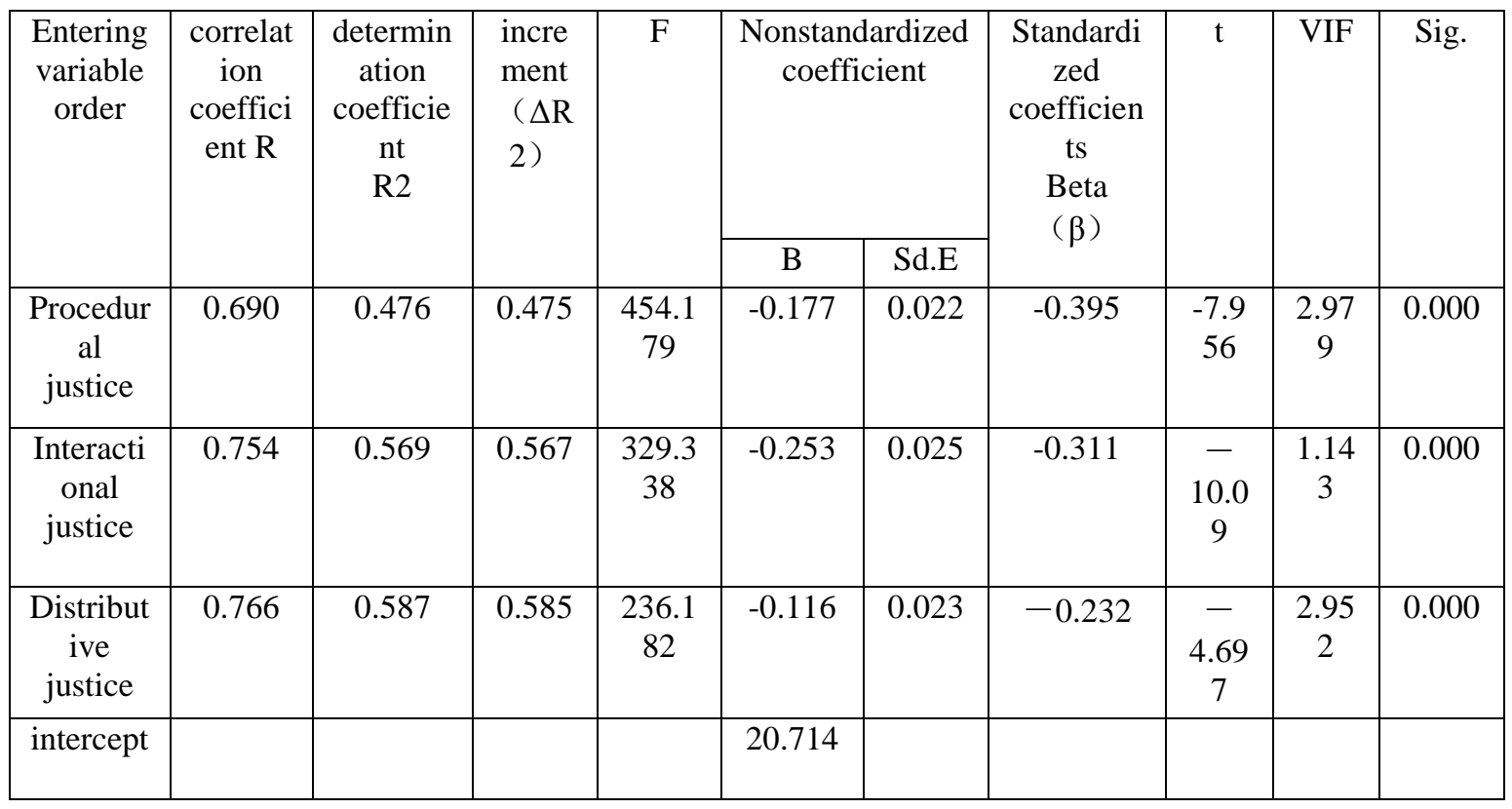

Table 3-2 organizational justice dimensions and the regression analysis result of turnover tendency

(2) The relationship of external job opportunities to organizational justice and turnover tendency

The study is used hierarchical regression model and takes the turnover tendency as dependent variable. The test result is shown in the following table 3-3, we input the control variable such as age, education, title and the procedural justice 、 distribute justice 、 interactional justice on model 2. The result show that the variable can affect the turnover tendency $(\mathrm{F}=205.483, \mathrm{p}<0.001)$; we input the control variable such as age , education、 title and the procedural justice、 distribute justice、 interactional justice 、 external job opportunity on model 3, it shows the organization justice can impact significant on turnover tendency( The change of $\beta$ value is procedural justice which is increase from -0.288 to -0.306 and the distribute justice is increase from 0.204 to -0.217 , while the interactional justice has no effect on turnover tendency $(\beta=-.045, p=.190>0.05)$

According to Baron and Kenny(1986) using regression method to validate the indirect effect, it can be found that the choice of organizational justice will impact on turnover tendency through external job opportunity. First, the choice of organizational justice will have a significant influence on turnover tendency of teacher. Second, the external job opportunity still has great effect on turnover tendency. From the estimation of model 2, we can be found the external job opportunity still have significant impact on turnover tendency. In other words, the choice of organization justice will influence on turnover tendency of teacher directly and it not needs the intervening effect by external job opportunity. 


\begin{tabular}{l|lll}
\hline \multicolumn{1}{c|}{ Variable } & Model 1 & Model 2 & Model 3 \\
\hline $\begin{array}{l}\text { Control } \\
\text { variable: Age }\end{array}$ & -0.258 & $0.115^{* * *}$ & $-0.263^{* * *}$ \\
$\begin{array}{l}\text { Educational } \\
\text { degree }\end{array}$ & $0.157^{* *}$ & $-0.108^{* *}$ & $0.162^{* * *}$ \\
$\begin{array}{l}\text { Title } \\
\text { Procedural }\end{array}$ & -0.070 & $-0.111^{* *}$ & $-0.075^{* *}$ \\
$\begin{array}{l}\text { justice } \\
\text { Distributive } \\
\text { justice }\end{array}$ & -0.288 & & \\
$\begin{array}{l}\text { Interactional } \\
\text { justice }\end{array}$ & -0.204 & $0.382^{* * *}$ & $-0.306^{* * *}$ \\
$\begin{array}{l}\text { External work } \\
\text { opportunity }\end{array}$ & -0.284 & $0.294^{* * * *}$ & $-0.217^{* * *}$ \\
\hline
\end{tabular}

$\begin{array}{lccc}\mathrm{F} \text { value } & 206.483^{* * *} & 8.700^{* * *} & 177.491^{* * * *} \\ \mathrm{R} & 0.845 & 0.720 & 0.846 \\ \mathrm{R}^{2} & 0.715 & 0.518 & 0.716 \\ \Delta \mathrm{R}^{2} & 0.711 & 0.512 & 0.711\end{array}$

ps : $*$ p $<0.05, * * \mathrm{p}<0.01, \quad * * * \mathrm{p}<0.001 ;$ The correlation coefficient of correlation model is the standard coefficient

Table 3-3 The correlation analysis of turnover inclination for organizational justice and job satisfaction

\section{Conclusion}

According to the research of Taiwan scholar Qiu Haozheng, he referred that below the 0.10 is the weak correlation or no correlation. The moderate correlation is from 0.40 to 0.69 while the highly correlation is from 0.70 to 0.99 , and the assessment standard for characteristic assessment standard for characteristic of complete related is 1.00 However, the result of the statistical analysis in this research shows that although the relation between not only organization justice and turnover tendency, but also individual cognitive external job opportunities and turnover tendency appears the significant correlated, but most of them are judged to moderate or minuend correlated according to the related coefficient values. Therefore, the correlativity between organization justice and turnover tendency shows the related coefficients of turnover tendency and organization justice(procedural justice, distributive justice and interactional justice) are $-0.690 、-0.655,-0.522$. Even though they are exist significant related, all of them are moderate related. It is also verified the research result of scholars such as Fields et al., Jiang Chunyan, Daly \& Geyer, Konorsky \& Cropanzano, Cohen-Charash \& Spector and so on. Distribute justice will have a better predict ability foe turnover willing than procedure justice and interactive justice. The respective explanation is $58.7 \%, 47.5 \%$, and $56 、 7 \%$, which is the same of the Masterson et al'reaserch.

According to the individual cognitive to the related correlation between external work opportunities and turnover tendency, it can be found that the related coefficient is 0.784 which is highly positive correlation and explanation is $61.3 \%$. It can be see from the verified of hypothesis 2 that the intervening effect for organization justice to external work opportunity and turnover tendency is still lack of empirically supported. This is accord the research result of Price. The college teacher's cognition for the level of external work opportunity will not be affected through the level of organizational justice.

\section{Acknowledgement}

The fund of the study comes from "Guangxi philosophy and social science planning in 2011" The management research of university student's occupation value and occupation career' (Project Code11BGL006).

\section{References}

[1] Adams,J.S.Inequity in social exchange.In L.Berkowitzled , Advances in Experimental Social Psychology[M].New York: Academic Press, 1965(In Chinese)

[2] Arnold, H. J., Feldamn, D. C. A. Multivariate Analysis of the Determinants of Job Turnover [J]. Journal of Applied Psychology, 1982, 63:350-360(In Chinese)

[3] Bies, R. J., Moag, J. S. Interactional Justice: Communication Criteria for Fairness [J]. In B. Sheppard (Eds.), Research on Negotiation in Organizations, 1986, 1:43-55(In Chinese)

[4] Price, J. L. Handbook of Organizational Measurement $[\mathrm{J}]$. International Journal of 
Manpower, 1997, 18:303-558.

[5] Thibaut, J., Walker, L. Procedural Justice: A Psychological Analysis [M] Hillsdale, NJ:Lawrence Erlbaum, 1975.

[6] LiuTingyang. Study on Fair Cognition and Job Performance of Untypical Employment. [A].Chinese Human Resource Management. (II)-Cross-strait dialogue. [C].BeiJing:Chinese economy press, 2007.

[7] LiJunyuan. A Study of Human Capital and
Labor Migration - The Theory and Practice in TaiWan. [D].TaiWan: Doctoral Essay of Political and Economy University , 2003.

[8] ZhangShuhan. Study on Recruits Personality Traits, Job Satisfaction and Turnover Tendency of College Staff. [D].Taiwan: Human Resource Management Institution of ZhongShan University,2004. 